\title{
EVALUATION OF ANTIBIOTICS USED IN PATIENTS WITH ACUTE RESPIRATORY INFECTIONS IN A HOSPITAL
}

\author{
PRICELLA AQWILLA GINTING*, AZIZAH NASUTION, KHAIRUNNISA KHAIRUNNISA
}

Department of Pharmacology, Faculty of Pharmacy, University of Sumatera Utara, Medan, Indonesia. Email: gintingpricella@gmail.com

Received: 22 November 2018, Revised and Accepted: 12 December 2018

ABSTRACT

Objective: This study evaluated the use of antibiotics in the treatment of patients with acute respiratory infection (ARI) in the outpatients installation in Bunda Thamrin General Hospital, Medan.

Methods: This prospective descriptive cohort study analyzed the use of antibiotics provided to patients with ARI using Indonesian universal health coverage known as Badan Penyelenggara Jaminan Sosial claims $(n=130)$ in outpatients installations from March to May 2018. The characteristics of the patients were organized and descriptively analyzed in Excel and SPSS programs. The antibiotics provided were grouped according to the Anatomical Therapeutical Chemical code and class; then, the dosage form, defined daily dose (DDD) units, was converted into milligrams. DDD calculation was done by dividing the total DDD usage with the total number of patients.

Results: Mean age of the patients was $32.12 \pm 10.579$ years. The highest quantity of antibiotic use in DDD/1000 patients-day units was cefixime reaching 1,897.435 mg DDD KPRJ.

Conclusions: Cefixime was the most widely available antibiotic for the treatment of ARI patients.

Keywords: Acute respiratory infections, Antibiotics, Anatomical therapeutical chemical/defined daily dose.

(C) 2019 The Authors. Published by Innovare Academic Sciences Pvt Ltd. This is an open access article under the CC BY license (http://creativecommons. org/licenses/by/4. 0/) DOI: http://dx.doi.org/10.22159/ajpcr.2019.v12i3.30890

\section{INTRODUCTION}

Acute respiratory infection (ARI) disease or often referred to as ARIs is infections caused by viruses or bacteria. This infection begins with heat accompanied by one or more symptoms: Throat pain or pain, runny nose, dry cough, or phlegm. ARI is always ranked first of the 10 most diseases in Indonesia [1].

In Medan, the incidence of ARI was 225,494 cases (47.62\%), and in Deli Serdang District, the cases of ARI were 12,871 cases $(31.7 \%)$ of the total population. Deli Serdang Regency and Medan are regions that have high rates of morbidity of ARI in infants [2]. As many as, $40 \%-60 \%$ of ARI cases were outpatients, while only $15-30 \%$ of them were treated as outpatients [3]. In Padang Bulan Health Center, Medan, ARI patients reached 19,038 cases in 2011. Cases of ARI increased to 21,536 in 2012 [4].

Based on Sarini's research (2015) on antibiotic use in the North Gorontalo Regency, it was proved that there were nine types of antibiotics used in ARI patients in district health centers, but only three types of antibiotics included in 90\% drug utilization segment, they were amoxicillin $500 \mathrm{mg}$, ciprofloxacin $500 \mathrm{mg}$, and cefadroxil $500 \mathrm{mg}$ [5]. A similar study conducted by Ratna found that antibiotics that have the highest bed-days (100 defined daily dose [DDD] per beddays) are ampicillin (22.4). The highest antibiotic with prescribed daily dose (PDD) and DDD values of 100 bed-days was cefotaxime with a PDD value of 154.3 and a DDD value of 100 bed-days at 16.7 [6].

\section{METHODS}

This research is a prospective cross-section descriptive study design. The required data were obtained from medical records and prescription of ARI patients at the outpatients installation of the Bunda Thamrin General Hospital, Medan, for March 2018-May 2018 which was approved by Health Research Ethical Committee (University of
Sumatera Utara; No:474/TGL/KEPK FK USU-RSUP HAM/2018). This study was conducted to determine the amount of antibiotic use in ARI therapy and to examine the use of antibiotics in patients using the Anatomical Therapeutical Chemical (ATC)/DDD methods. Inclusion criteria in this study were outpatients diagnosed with ARI and received antibiotic therapy. Exclusion criteria were pregnant patients and suffered from HIV and cancer. As many as, 130 patients diagnosed ARI met inclusion criteria in the study period. Patients data recorded on the data collection sheet included: Patients age, gender, and medication used. Recorded data on ARI drug types used include dosage form, dosage, and number of uses.

The ATC classification is based on the antibiotic code, the DDD calculation of each antibiotic is obtained by the total number of drugs that say in milligrams. The results of the use of antibiotics per patients were carried out using DDD/1000 patients. Data from the DDD/1000 patients calculations were changed in the form of percentages and then cumulative. All analyses patient's characteristics were done using Microsoft Excel and SPSS Statistics version 16.0 (SPSS Inc.). $p=0.05$ looks statistically significant. This natural medicine is obtained from an e-catalog. This research is disastrous by the organizers of research and ethics at the University of Sumatera Utara. It was carried out in accordance with ethical standards provided by the University of Sumatera Utara, Faculty of Medicine.

\section{RESULTS}

Of 139 patients, only 130 patients met the inclusion criteria. Characteristics of these patients included gender and age of patients are presented in Table 1 . Based on the gender of patients diagnosed with ARI during March-May 2018 period, of 130 patients, it was evident that most (59\%) of the patients were male, while only $42 \%$ of them were female. However, based on the results of statistical analysis, there were no significant differences between the number of male and female patients $(p=0.586)$. 
Table 1: Characteristics of the patients with ARI $(n=130)$ in Bunda Thamrin Hospital

\begin{tabular}{lllll}
\hline No & Age group (years) & Male & Female & n (\%) \\
\hline 1 & Early teenager (12-16) & 5 & 3 & $8(6.15)$ \\
2 & Late teenager (17-25) & 14 & 13 & $27(20.76)$ \\
3 & Early adult (26-35) & 33 & 20 & $53(40.76)$ \\
4 & Late adult (36-45) & 18 & 8 & $26(20)$ \\
5 & Early elderly (46-55) & 6 & 7 & $13(10)$ \\
6 & Late elderly (56-65) & 0 & 3 & $3(2.30)$ \\
Total number & 76 & 54 & $130(100)$ \\
\hline
\end{tabular}

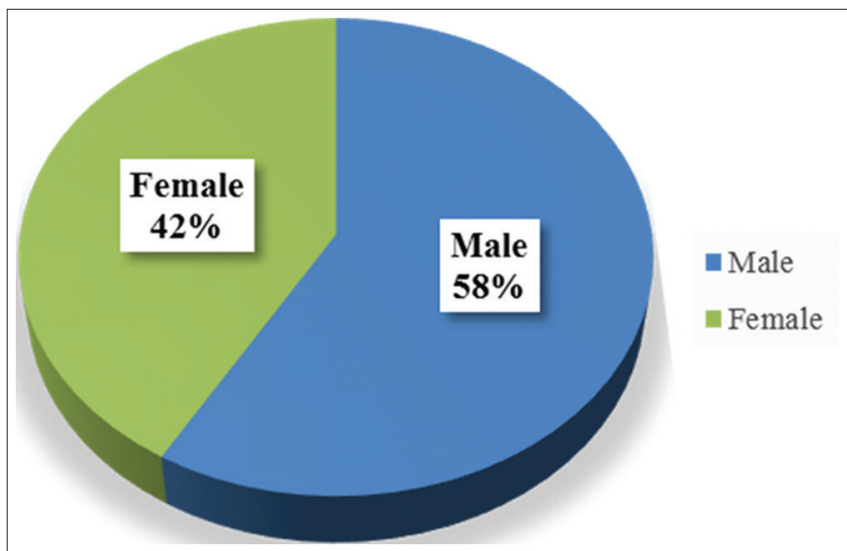

Fig. 1: Characteristics of acute respiratory infection patients based on gender

Based on the characteristics of the gender group of 130 ARI patients from March to May 2018, there were 76 males (58.461\%) and 54 females $(41.538 \%)$. Based on the results of statistical analysis, there were no significant differences between the number of male and female patients $\mathrm{p}=0.586(\mathrm{p}<0.05)$. A research conducted by Ahyanti about relationship between smoking and the incidence of ARI in students in tanjung reef (2013), showed that various risk factors that increase the incidence of ARI are with male gender. Proven with the results of the study, from the students suffering from ARI, $58.0 \%$ of them were manifold male gender, $\mathrm{p}=0.041$, meaning there is a meaningful relationship between genders with ARI [7].

The pattern of antibiotic use in outpatients with ARI based on diagnosis is shown in Figs. 1 and 2.

Of the six age groups of the patients, it was found that the age group of 26-35 years had the highest prevalence with amount of 53 patients (40.76\%), followed by $17-25$ years was 27 patients $(20.76 \%)$, age group of $36-45$ years was 26 patients $(20 \%)$, and the age group of 46-55 years had a percentage of 13 patients $(10 \%)$, compared to the age group of $12-16$ years had a percentage of 8 patients $(6.15 \%)$ while the lowest number of patients was in the 56-65 years age group of 3 patients $(2.30 \%)$. The results of statistical tests for age groups showed no significant differences with $\mathrm{p}=0.098(\mathrm{p}<0.05)$. The mean age of the patients was $32.12 \pm 10.58$ years.

In the ATC classification system, active substances are divided into different groups according to the organ or system where the drug works and produces therapeutic, pharmacological, and chemical properties [8]. Based on the classification system by the WHO Collaborating Center, classification of the antibiotic use from the 130 patients was obtained. The present study found three classes of antibiotics that they were cephalosporin, macrolide, and quinolone, consisting of cefixime, cefadroxil, azithromycin, clarithromycin, levofloxacin, and ciprofloxacin of antibiotics used in the treatment of ARI (Table 3). In this study, the data of the cephalosporin group were divided into two types, namely cefixime and cefadroxil, while the macrolide antibiotic group consisted of azithromycin and clarithromycin, and the latter was divided into two types, namely levofloxacin and ciprofloxacin.

DDD is the assumption that the average dose per day of antibiotic uses for certain indications in adults. To obtain standard data and to be able to compare data elsewhere, the WHO recommends the classification of antibiotic use by ATC classification (Table 3) [9].

Evaluation of the use of antibiotics from 130 patients in Medan General Hospital, Medan, was carried out using the calculation of DDD 1000 patients-days. This study found that there are 6 types of antibiotics that used in the treatment of ARI patient with a total value of DDD/1000 patients-days of 7,239.73 and an average of $1,206.62$ for the 6 types of anitbiotics based on the ATC code and the standard value of WHO DDD (in mg).

Based on the data obtained then the calculation of the quantity of antibiotic is used by following the rules established by the WHO Collaborating Center 2011. Antibiotics are grouped according to the ATC code and class; then, the dosage form is adjusted to the definitive DDD units of each antibiotic use by patients. The definitive DDD unit uses milligram, so the unit of antibiotic dose must be converted into milligrams first [10].

\section{DISCUSSION}

The highest prevalence of patients in the age group of ARI patients is the age range of 26-35 years with a percentage of 53 patients (40.76\%). The results of statistical tests for age groups showed no significant differences with $\mathrm{p}=0.098(\mathrm{p}<0.05)$, different from the research conducted by Marniati, in 2017, on the analysis of causal factors on the incidence of ARI, namely the frequency of the age of respondents with ARI in the region of West Aceh health centers with the highest number: Age 36-40 years 38 people (37.8\%) [11]. According to the WHO in 2014 sStates that the causes of acute respiratory tract infections vary widely, the onset of symptoms can take place starting from hours to days after the onset of infection. The symptoms of this disease consist of fever, coughing, and frequent sore throat, runny nose, shortness of breath, wheezing, or difficulty breathing. Pathogens that cause acute respiratory tract infections are influenza virus, parainfluenza virus, rhinovirus, respiratory syncytial virus, and severe respiratory syndrome coronavirus [12].

Based on the data of ARI patients, it was found that the highest number of patients based on gender were male patients with the number 76 patients $(58,4 \%)$ obtained by dividing the number of male patients with the total number of patients then multiplied by $100 \%$, this is the same as research in Mei Ahyanti's about smoking relationship with the incidence of ARI in students in Tanjung reef (2013). Proven with the results of the study, from the students suffering from ARI, $58.0 \%$ of them were manifold male gender, $p=0.041$, meaning there is a meaningful relationship between genders with ARI [7].

From the classification of the WHO Collaborating Center, the data obtained were 130 cases, March-May 2018 use by ARI patients, treatment profiles of ARI patients in outpatients installations distributed into three classes of drugs and six types of antibiotics. The highest use of antibiotics in patients with ARI is azithromycin antibiotic. This is based on the activity of azithromicin which has more potent antibacterial activity to gram negative, wider distribution volume and longer half-life so that it is preferred for respiratory tract infections (Table 2) [13].

Based on the data obtained, the calculation of the quantity of antibiotic is used by following the rules established by the WHO Collaborating Center 2011. Antibiotics are grouped according to the ATC code and class; then, the dosage form is adjusted to the definitive DDD units of each antibiotic use by patients. The definitive DDD unit uses milligram, so the unit of antibiotic dose must be converted into milligrams first [10]. Based on the study, "evaluation of the use of antibiotics in ARIs in the pediatric group at the Yogyakarta 
Table 2: Class of antibiotics

\begin{tabular}{lllll}
\hline Class of antibiotics & ATC code & Type of antibiotics & Preparation & Strength of preparation \\
\hline Cephalosporin & J01DD08 & Cefixime & Oral & 200 \\
& J01DB05 & Cefadroxil & Oral & 500 \\
Macrolide & J01FA10 & Azithromycin & Oral & 500 \\
& J01FA09 & Clarithromycin & Oral & 500 \\
Quinolone & J01MA12 & Levofloxacin & Oral & 500 \\
& J01MA02 & Ciprofloxacin & Oral & 500 \\
\hline
\end{tabular}

ATC: Anatomical therapeutical chemical

Table 3: Quantity of antibiotic use in ARI patients in DDD/1000 patients-day unit

\begin{tabular}{llll}
\hline ATC code & Type of antibiotics & DDD standards value of the WHO (mg) & DDD/1000 patients-day \\
\hline J01DD08 & Cefixime & 400 & 1223.076 \\
J01FA10 & Azithromycin & 300 & 1897.435 \\
J01DB05 & Cefadroxil & 2000 & 265.38 \\
J01MA12 & Levofloxacin & 500 & 115.38 \\
J01MA02 & Ciprofloxacin & 1000 & 69.23 \\
J01FA09 & Clarithromycin & 500 & 153.85 \\
Amount & & & 7239.73 \\
Average & & & 1206.62 \\
\hline
\end{tabular}

ATC: Anatomical therapeutical chemical, DDD: Defined daily dose

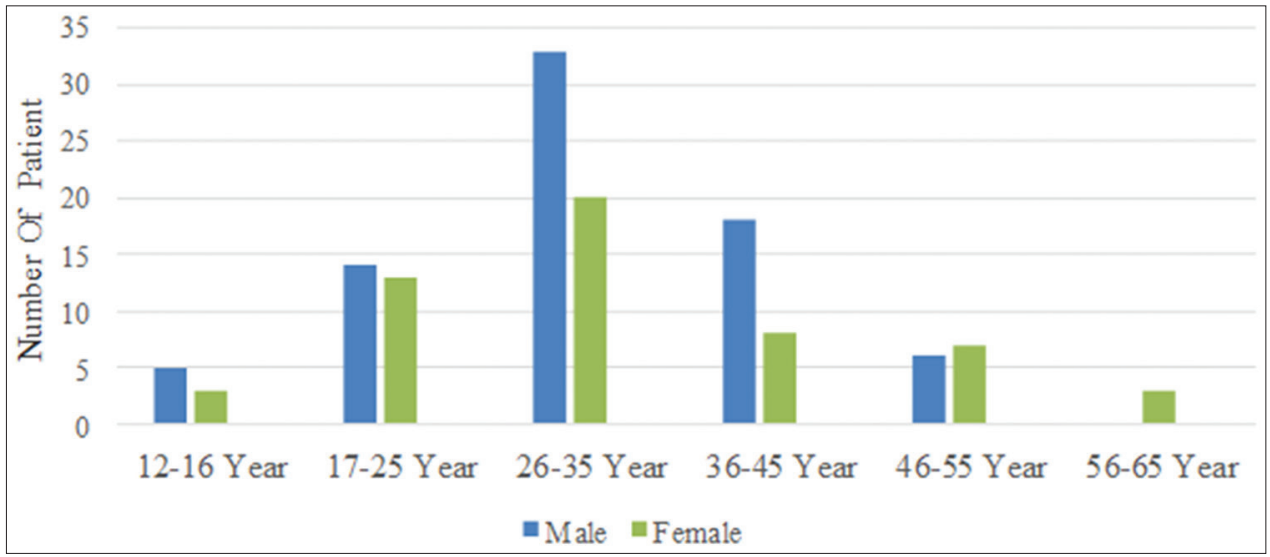

Fig. 2: Characteristics of the patients according to age

inpatients hospital in July-September 2013" obtained data from 16 ARI patients who used antibiotic therapy, there were six types of antibiotics used, namely cefixime, amoxicillin, ceftriaxone, cefotaxime, erythromycin, and paromomycin sulfate. The highest use of antibiotics was cefixime that reached as much as 36.84\% [14]. The antibiotics prescribed in ARI patients need more attention by health professionals $[15,16]$

\section{CONCLUSIONS}

Most patients with ARI were male with the age range of 26 years -60 years. The mean value of patients age was $32.12 \pm 10.58$ years. Azithromycin was the most widely available antibiotic for the treatment of ARI patients, with the ATC code, J01FA10 indicating the location organ where the drug of work and the type of antibiotic. Azithromycin has a usage quantity of 1,897.435 DDD/1000 KPRJ-day. This study is limited by the small sample size and the patients' admission period from which the data were extracted. In the future, large-scale research is needed to get more accurate results.

\section{AUTHORS' CONTRIBUTIONS}

All the authors have contributed equally.

\section{CONFLICTS OF INTEREST}

The authors declare that they have no conflicts of interest.

\section{REFERENCES}

1. RI Ministry of Health: Indonesian Health Profile. Jakarta (Indonesia): Ministry of Health Republic of Indonesia; 2014.

2. Agustama A. Study of Acute Respiratory Infections (ARI) in Children under Five in the City of Medan and Deli Serdang District. Thesis, University of Sumatera Utara; 2005. p. 1-72.

3. Dirjen PP. Technical Guidelines for Clinical Co-Infection of TB-HIV. Jakarta (Indonesia): Directorate General of Disease Control and Environmental Health, Ministry of Health Republic of Indonesia; 2012.

4. City Health Office: Health Profile of North Sumatera Province in 2012. Medan (Indonesia): City Health Office; 2012.

5. Pani S. Monitoring of the use of Antibiotics ATC/DDD Method and DU 90\%: Observational Studies in all Puskemas of North Gorontalo district. Thesis, Padjajaran University; 2015. p. 35-47.

6. Ratna PD. Evaluation of the Use of Antibiotics Based on the PDD (Prescribed Daily Dose) Method and DDD (Defined Daily Dose) on Inpatients in the Children's Ward Panembahan Senopati Hospital Bantul Yogyakarta Period January - June 2014. Thesis University of Sanata Dharma; 2015. p. 23-34.

7. Ahyanti M, Duarsa AB. The relation of smoking with the incidence of ARI in students of the Tanjung Karang health-care polytechnic. Public Health J 2013;7:47-51.

8. World Health Organization (WHO). Guidelines for ATC Classification and DDD Assignment. Geneva: WHO; 2015.

9. Gould IM. A review of the role of antibiotic policies in the control of antibiotic resistance. J Antimicrob Chemother 1999;43:459-65.

10. Costa SD, Basri M, Shamsudin N, Basri H. Stability of positively 
charged nanoemulsion formulation containing steroidal drug for effective transdermal application. J Chem 2014;2014:1-8.

11. Marniati M, Yarmaliza Y. Factor Analysis of the Incidence of ARI. National USM Seminar; University of Meulaboh; 2014. p. 2-17.

12. World Health Organization (WHO). Guidelines for ATC Classification and DDD Assigment. Oslo, Norway: WHO Collaborating Center For Drug Statistics Methodology; 2014. Available from: Available from: http://www.whoc. [Last accessed on 2018 Sep 28].

13. American Society of Health-System Pharmacy. AHFS Drug
Information. USA: ASHP Incoporation; 2010.

14. Fajarwati AH. Evaluation of the Use of Antibiotics in Acute Respiratory Infections in the Pediatric Group at the Yogyakarta Inpatients Hospital in July-September 2013. Thesis University of Sanatha Dharma; 2015. p. 1-15.

15. Muslim Z. Antibiotic prescription to pediatric in hospital Bengkulu, Indonesia: ATC/DDD Index. Int J Pharm Pharm Sci 2018;10:31-4

16. Herawati F, Hartono ID, Pranajaya D, Narindra IP. Antibiotic use at primary healthcare centers in Surabaya: A surveillance study. Int J Pharm Pharm Sci 2017;9:41-4. 